\title{
Electronic Commerce in Web 3.0: THE EVIDENCE FROM EMERGING ECONOMICS
}

\author{
Xi Zhang ${ }^{1}$ and Doug Vogel ${ }^{2}$ \\ ${ }^{1}$ Institute of Policy and Management, Chinese Academy of Sciences, P. R. China \\ xizhang@casipm.ac.cn \\ ${ }^{2}$ Information Systems Department, City University of Hong Kong
}

\begin{abstract}
Web 3.0 or so called "Internet 3.0" is a popular 3D internet application. The emerging economics burgeoning Internet population will soon have an array of Web 3.0 in which to work and play. Although some strategies of web 3.0 platforms have been proven to be successful for attracting user acceptance in the developed countries, the effects of these strategies are questionable in the market of emerging economics. In this study, we investigate the Web 3.0 market and e-commerce strategies in one of biggest emerging economics in the world. Based on the uses and gratifications theory, this study compares the different strategies of these local companies, and tries to explain which difference of e-commerce strategies between these competitors, and how can these Web 3.0 competitors survive in the environment of emerging economics. Limitations and Implications are discussed in the end.
\end{abstract}

\section{Keywords}

Web 3.0, Emerging Economics, Electronic Commerce, Customer Relationship

\section{INTRODUCTION}

As an important internet business market with more than 210 million internet population, China is getting into Web 3.0. Web 3.0 is a computer-based simulated 3D environment intended for its users to inhabit and interact via avatars [1]. There are many synonyms for Web 3.0, such as "Web 3.D" [2], and "3D World" [3]. Second Life, the world famous Web 3.0 platform, has developed its business plan for marketing in mainland China. However, based on "western model", Second Life may face several dilemmas on its application in China. One of most salient challenge is that Chinese users will actually adopt Second Life for communication and real business. One report shows that by 2007, the active users there are only five thousand Chinese users very active in Second Life accounting for $0.92 \%$ of total avatar count. In the same time, Second Life will also face the competition from some local web 3.0 platforms. $\mathrm{HiPiHi}$, which focuses on innovative business model, currently has more than 100,000 users and claims it will become the biggest Web 3.0 platforms in mainland China. Novoking and Uworld, other two biggest local Web 3.0 platforms, emphasize on entertainment and hope them can attract most Chinese young users. In Chinese Web 3.0 market, how to attract the acceptance of Chinese users become the emerging critical technology and management themes for different Web 3.0s.

In this research, we will conduct a case study to understand how these competitors' different strategies impact on user acceptance in Chinese environment, and investigate the following research questions: Which e-commerce strategies are different between these local competitors? How these different strategies impact on user acceptance in China? Is there any other important DOI : $10.5121 /$ ijcsit.2011.3317 
strategies should be promoted these Web 3.0 platforms have not focused? In this study, we adopt technology acceptance model (TAM) and uses and gratifications (U\&G) theory as overarching theory and develop the theoretical framework on antecedents of Web 3.0 acceptance. Then, we investigate how these competitors' different strategies impact on these antecedents. The data collected in this study consists of documentation, interviews, and direct observations.

\section{THEORETICAL BACKGROUND}

\subsection{Environment of Emerging Economics}

Unlike developed countries, China is an emerging market with some special environments. When Web 3.0 platforms conduct business in China, the strategies need to be adapted to the Chinese environment. From the institution-based view, strategies of firms from different countries differ for different institutional environments [4]. At the national level, the institutional environment can be defined as formal with informal constrains that structure human interaction [5]. Any strategic choice that firms make is inherently affected by the formal and informal constraints. The formal environment consists of politics, law, and society (e.g., ethical norms) [6]. The informal environment is related to national culture [7]. Technology environment is another formal constraint which influences the strategic choice of firms. We propose three types of environments that may affect the strategic choice of Web 3.0 platforms: government policy, Chinese culture and technology environment.

\subsection{E-Commerce Strategies of Web 3.0 Platforms}

User acceptance is determined by perceptions of whether the Web 3.0 vendors provide sufficient encouragement, guidance, and incentives for using Web 3.0 platforms. Several strategies can be promoted by Web 3.0 platforms to gain user acceptance [8]. This paper investigates the strategies of Web 3.0 vendors from the perspective of customer relationship management (CRM).

CRM processes can be divided into two stages: 1) initiation stage: the objective is to acquire customers; 2) maintenance stage: the objective is to regain customers by maintaining good relationships with them [9]. In the initiation stage, Web 3.0 companies choose different strategies to attract first-time users and win back dissatisfied customers. In this stage, CRM strategies can be categorized from three perspectives, i.e., technology solution, business strategy and customer strategy [10]. In the maintenance stage, Web 3.0 companies choose strategies to regain customers by maintaining good relationships with them. In this stage, the culture of Web 3.0 should be proactively promoted to encourage good communication. Thus, based on the framework of CRM, we compare four types of strategies of Web 3.0 platforms as following: 
International Journal of Computer Science \& Information Technology (IJCSIT), Vol 3, No 3, June 2011

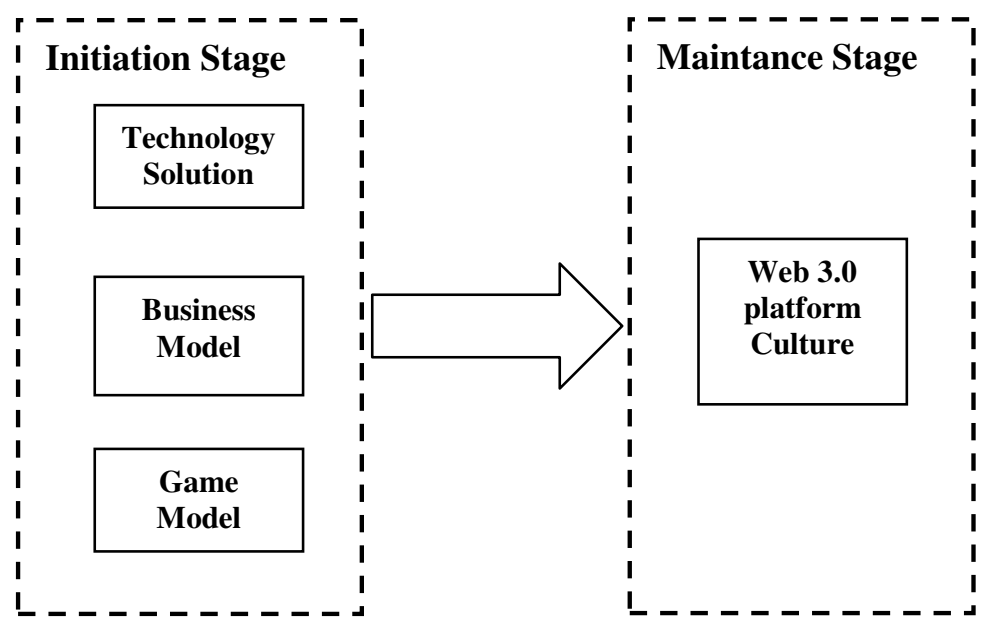

Figure 1. Research Foundations of E-Commerce Strategies

(1) Technology Solution (TS): The TS strategy is how HiPiHi, Uworld and Novoking develop their technology approach and solutions to suit the Chinese network or hardware environment. There are four sub-strategies of TS, i.e., interfaces, networks, user hardware and server requirements.

(2) Business Model (BM): The BM strategy is how these three Web 3.0 platforms support virtual business in the game. There are at least two sub-strategies of BM, i.e., virtual property policies and exchange systems.

(3) Game Model (GM): The GM strategy is how to support users to play in these three Web 3.0 platforms. There are two sub-strategies of GM, i.e., creation models and task orientations.

(4) Web 3.0 platform Culture (VWC): VWC strategy is how these three Web 3.0 platforms promote virtual culture in the game to suit the Chinese environment and users' personal values. There are at least three sub-strategies of VWC, i.e., social networks, virtual society rules, and extent of virtuality.

\subsection{Determinants of User Acceptance}

In this study, we focus on Chinese users' acceptance of Web 3.0 platforms. We first incorporate core constructs of the Technology Acceptance Model (TAM) as our guiding theory. TAM has two core constructs influencing users' technology acceptance behavior: perceived usefulness (PU) and perceived ease of use (PEOU) [11]. As the best known theory in information systems, TAM has been used extensively for understanding user acceptance of different information technology, e.g., groupware acceptance [12], online games adoption [13], enterprise systems adoption [14], mobile games acceptance [15], e-learning system adoption [16], e-payment system acceptance [17], and web 2.0 acceptance [18].

Despite the extensive uses of TAM, researchers recently suggest that the two dimensions are too narrow and shine light on only a part of technology acceptance and use. Further, they believe that more factors from other aspects (such as emotional reactions and social factors) should be included to explain acceptance more consistently and comprehensively [19, 20]. Thus, some new factors have been proposed to better explain the acceptance of IT applications. For example, Venkatesh et al. [21] who proposed TAM2 include, a new factor with subject norms (SN), which is the degree of individual perceptions of external pressures when 
performing the behavior. TAM2 is widely adopted in studies of social network software. In the online entertainment field, some researchers have also proposed "perceived enjoyment" (PEN) of playing as the intrinsic motivation of user acceptance [13, 15]. Based on the definition of Web 3.0, it provides a virtual society in which people can work and play. It has the characteristics of social network software and online entertainment. Thus, we propose our general model of user acceptance of Web 3.0 platforms with four dimensions and develop measures for each dimension.

We first incorporate core constructs of the uses and gratifications (U\&G) theory as our guiding theory. U\&G theory focuses on explaining users' motivation and associated behaviors [22]. According to U\&G theory, people's motivations on using IT can be divided into three dimensions: utilitarian, entertainment, and social motivation [22]. These three dimensions are all motivations of user acceptance of 3D Web 3.0 platforms, as it has the characteristics of ecommerce, games, and social networks [23]. Thus, we propose our general model of user acceptance of Web 3.0 platforms with the three dimensions, and develop constructs for each dimension.

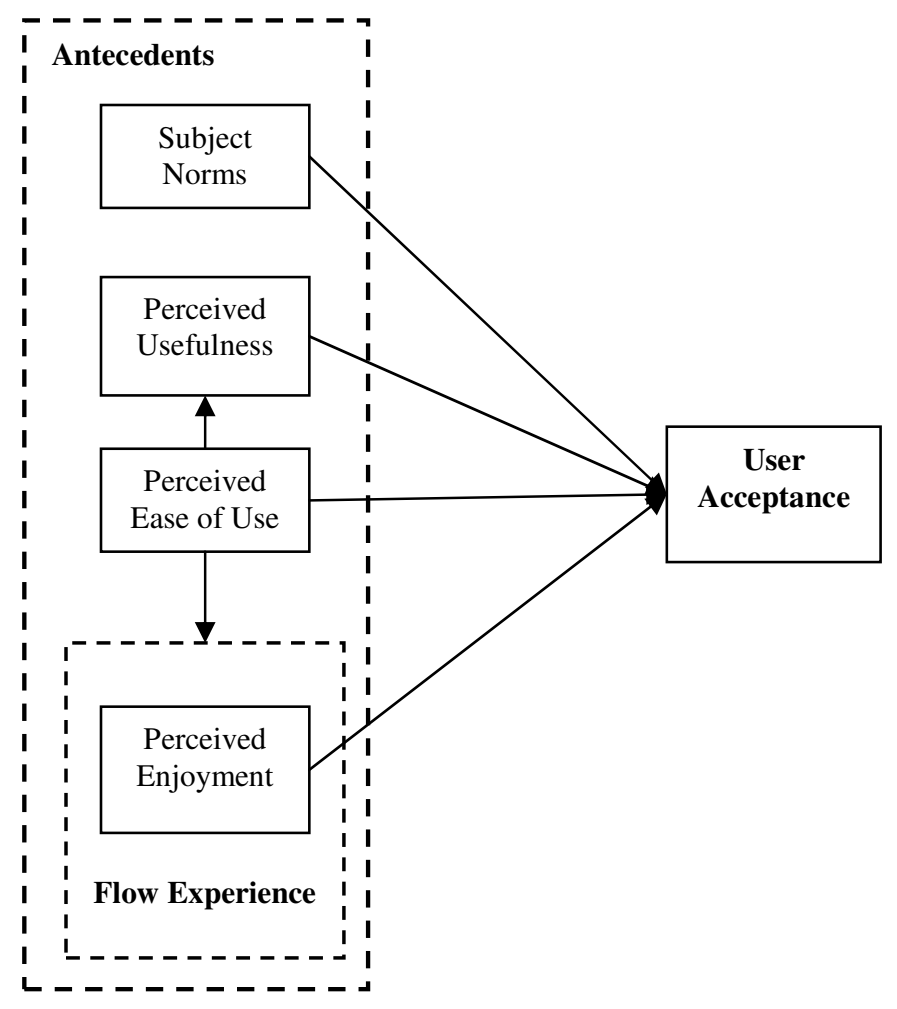

Figure 2. Integrated Model of TAM and TAM2

(1) Utilitarian dimension: The research stream, based on a utilitarian perspective, is rooted in the technology acceptance model (TAM) [24]. TAM has two core constructs influencing users' technology acceptance behavior: perceived usefulness (PU) and perceived ease of use (PEOU) [11]. PU is measured by two factors, i.e., efficiency and effectiveness [11]. PEOU is measured by three factors, i.e., skillfulness, quickness, and ease of learning [11]. 
(2) Entertainment dimension: Based on the entertainment perspective, some new factors have been proposed to better explain the acceptance of entertainment-oriented IT applications. For example, in the online entertainment field, some researchers have also proposed "perceived enjoyment" (PEN) of playing as the intrinsic motivation of user acceptance $[13,15]$. PEN is measured by three factors, i.e., enjoyable, pleasant, and fun [25].

Social dimension: From the social perspective, an important motivation of users accepting social software is establishing social networks with others. In the literature, the most adopted construct is subject norms ( $\mathrm{SN}$ ), which is the degree of individual perceptions of external pressures when performing the behavior [21]. SN is measured by two factors, i.e., influencing people, and important people [21].

\section{RESEARCH APPROACH}

\subsection{Research Framework}

This paper investigates how the four strategies of Web 3.0 platforms (technology solutions, business models, game models and Web 3.0 platform culture) impact on four determinants of user acceptance behavior (perceived of ease of use, perceived usefulness, perceived enjoyment and subject norms) in the Chinese environment. Three local competitors (HiPiHi, Uworld and Novoking) were chosen in order to compare their strategies and ascertain possible impacts on user behaviors. The theoretical framework of comparison is illustrated in Figure 3.

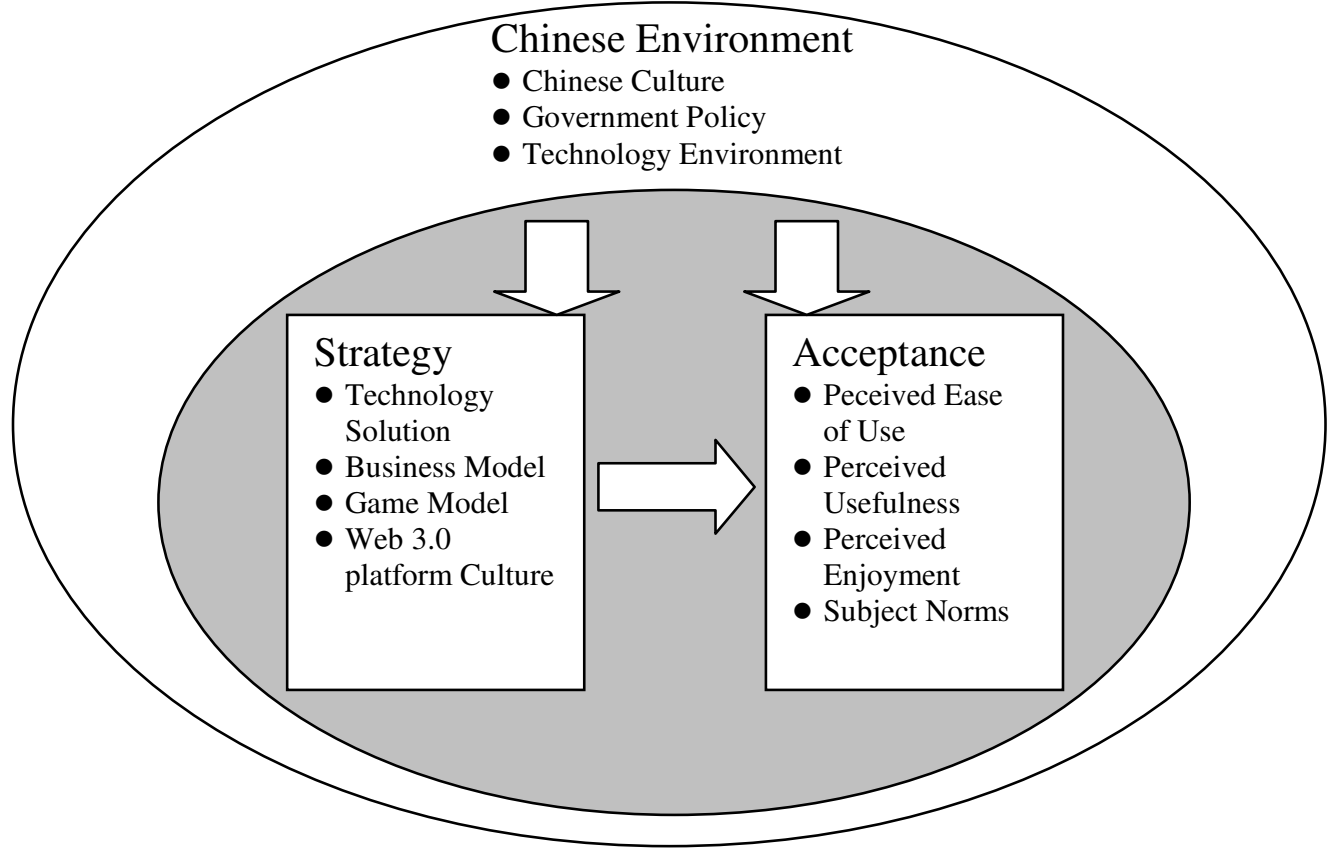

Figure 3. Research Framework of Case Study

\subsection{Coding Scheme}

For ease of recording the comparison results, we designed a coding scheme to guide the coding process, as illustrated in Appendix 1. 
International Journal of Computer Science \& Information Technology (IJCSIT), Vol 3, No 3, June 2011

(1) Perceived Ease of Use (PEOU): PEOU is "the extent to which a person believes that using a particular technology will enhance job performance" [11]. The following three measures are factors affecting levels of PEOU based on literature [11]. PEOU is measured by the extent to which these factors are present or not.

- Skillfulness: Whether it is easy for users to become skillful as using HiPiHi, Novoking, or Uworld.

- Quickness: Whether it is quick for users to learn to use HiPiHi, Novoking, or Uworld to interact.

- Learning: Whether learning to use HiPiHi, Novoking, or Uworld is easy for users.

(2) Perceived Usefulness (PU): PU is "the degree to which a person believes that using the system will be free from effort" [11]. The following measures are factors affecting levels of PU based on the literature [11]. PU is measured by the extent to which these factors are present or not.

- Efficiency: Whether users enhance work efficiency by using HiPiHi, Novoking, or Uworld.

- For example, whether users could reduce cost by doing business via the platform.

- Effectiveness: Whether HiPiHi, Novoking, or Uworld enhances user effectiveness or performance. For example, whether they can earn real money in it.

(3) Perceived Enjoyment (PEN): PEN is the extent to which the activity in question is perceived to be enjoyable, apart from any performance consequences or utilitarian considerations [26]. The following three measures are factors affecting levels of PEN based on the literature [25]. PEN is measured by the extent to which these factors are present or not.

- Enjoyable: Whether users find using HiPiHi, Novoking, or Uworld to be enjoyable.

- Pleasant: Whether the actual process of using HiPiHi, Novoking, or Uworld is pleasant.

- Fun: Whether users have fun using HiPiHi, Novoking, or Uworld.

(4) Subject Norms ( $\mathrm{SN}$ ): $\mathrm{SN}$ is the degree of individual perception of external pressure that one should perform the behavior [21]. The following two measures are factors affecting levels of SN based on the literature [21]. SN is measured by the extent to which these factors are present or not.

- Influencing People: Whether people who influence user behavior believe they can use HiPiHi, Novoking, or Uworld.

- Important People: Whether people who are important to users think that they can use HiPiHi, Novoking, or Uworld.

\subsection{Data Collection}

Data collection lasted from August 2009 to November 2010. We used third-party search engines (e.g., Google.com) to collect related documentation. For the first-round of information search, we used 11 Chinese key words: "Chinese Web 3.0 platform,", "HiPiHi,," "Uworld,," and "Novoking.." For the second-round search, we combined these key words to narrow the 
search scope. In the end, we found 200 useful web pages, including news, third-party reports and magazine articles. In 2010, we conducted the third-round search to add new observation and modify data, and sample data extended to nearly 300 web pages.

The comparison was supported by secondary data collected from a variety of sources: 1) direct observations in three Web 3.0 platforms; 2) records of user comments from well known online forums, such as "forums.hipihi.com"; and 3) reports from third party research groups regarding Chinese Web 3.0 markets. Two researchers independently analyzed web logs and summarized the evidence using the coding scheme.

\section{Case Description}

HiPiHi World (www.hipihi.com) was launched in July 2005 and is considered to be one the biggest Web 3.0 platforms in Mainland China. HiPiHi was founded by Hui Xu and Xinhua Lu, both Internet entrepreneurs with significant web experience. It has adopted Second Life's spirit which focuses on "free creation,," and expects to be the "Chinese Second Life.." By November 2009, it had more than 95,000 registered users.

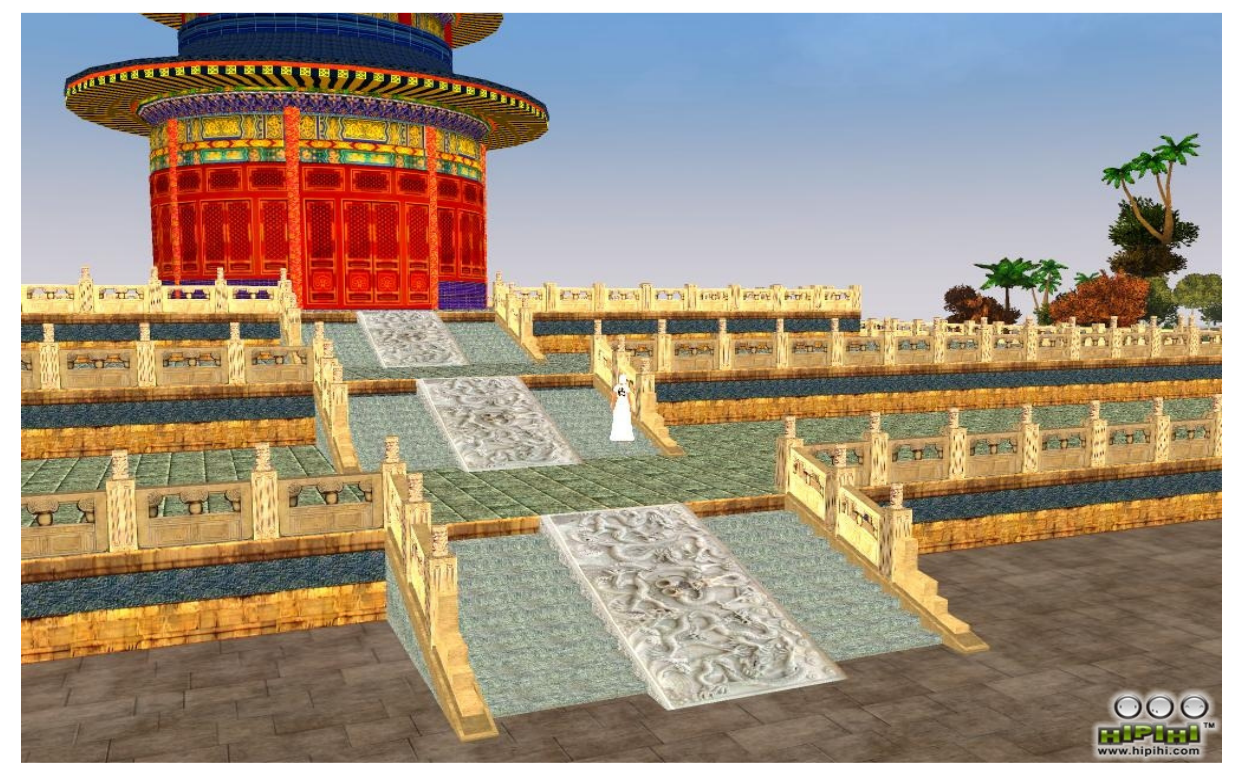

Figure 4. Interface of HiPiHi

Uworld (www.uworld3d.com) was invested by venture capital providers in early 2006. Its spirit is "helping users to create real value." Designers claim they expect to design Uworld as a 3Dbased natural human computer interaction (NHCI) platform, where people can establish social connections. 
International Journal of Computer Science \& Information Technology (IJCSIT), Vol 3, No 3, June 2011

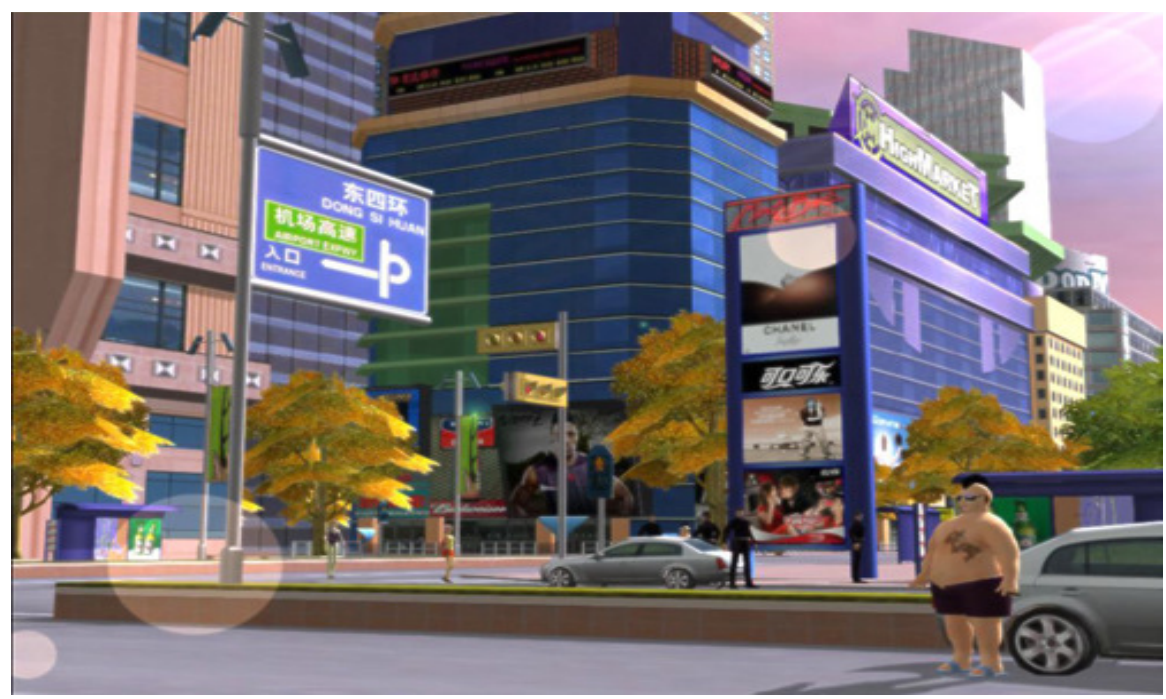

Figure 5. Interface of Uworld

Novoking (www.novoking.com.cn) was launched in November 2005. The target market of Novoking is female with 18-25 year olds who live in cities. To attract these users, it has provided some rather innovative strategies to suit the Chinese Internet environment and user characteristics. Currently, it has more than 10,000 registered users.

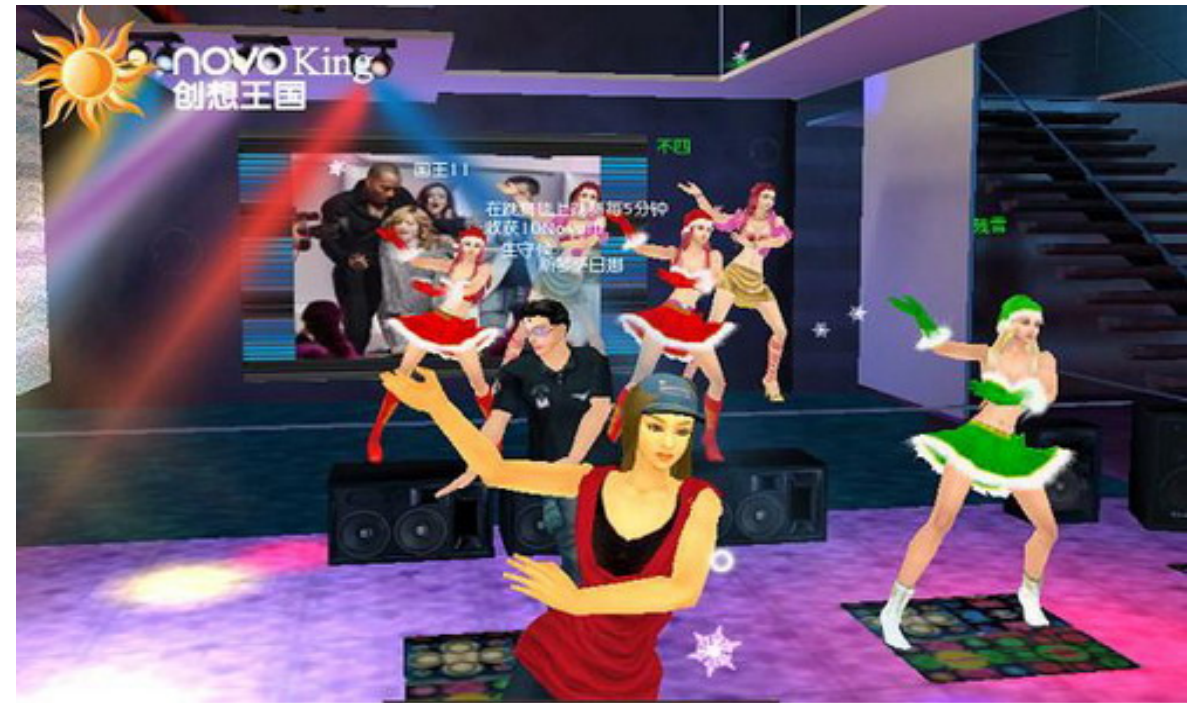

Figure 6. Interface of Novoking

\section{Case Analysis}

\subsection{Coding Process}

In our comparison analysis, we use the form of matrices to present the information systematically to the reader, and enable the identification of coding procedures to reduce information of categories [27]. The stage of the coding process is shown as following: 


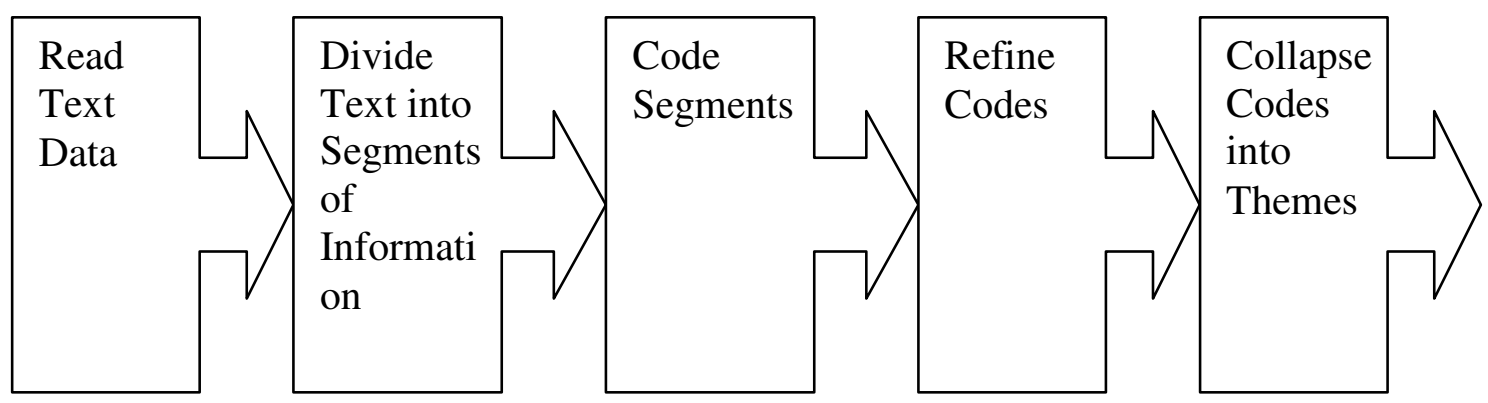

Figure 7. Coding Process

\subsection{Influence of Strategies on User Acceptance}

Based on the research framework, we compared the three Web 3.0 platforms, and investigated how these different strategies impact on user acceptance in China. The results of the comparison are summarized in Table 1, 2, 3, 4. For example, "(PEOU-QUI)+" under "Uworld" indicates that the that "technology solution" of Uworld has a positive impact on the dimension "quickness (LEA)" of user "perceived ease of use (PEOU)" in the Chinese environment.

Technology Solution (TS): First, the interface of HiPiHi is more complex than that of the other two Web 3.0 platforms. This complex interface may lead to difficulties in Chinese users becoming skillful. Second, the average network requirements for running Uworld and Novoking are $56 \mathrm{~K}$, which can be supported in most parts of China. The low network requirement may lead to Chinese users being able to access Web 3.0 platforms quickly. Third, Novoking has developed an innovative technology solution to reduce user hardware and server requirements. Based on internal tests, Novoking can support one million online users. This innovative technology can enhance the users' efficiency.

Table 1. Influence of TS on User Acceptance

\begin{tabular}{|c|c|c|c|}
\hline & HiPiHi & Uworld & Novoking \\
\hline \multirow{4}{*}{$\begin{array}{l}\text { Technology } \\
\text { Solution (TS) }\end{array}$} & (PEOU-SKI)- & (PEOU-SKI)+ & (PEOU-SKI)+ \\
\hline & (PEOU-QUI)- & (PEOU-QUI)+ & (PEOU-QUI)+ \\
\hline & (PU-EFI)- & (PU-EFI) & (PU-EFI)+ \\
\hline & (PU-EFI)- & (PU-EFI) & (PU-EFI)+ \\
\hline
\end{tabular}

Note: “+” means positive; “-” means negative; “ ” means average impact.

Business Model (BM): As free exchange of virtual currency is forbidden in Mainland China, three Web 3.0 platforms have provided their innovative business strategy. HiPiHi users can earn money by selling virtual land. But this business model is too simple. Compared with $\mathrm{HiPiHi}$, the business strategy of Uworld and Novoking are more flexible. Uworld users can establish clubs, and earn money from the fees of membership and some value-added service. Novoking users can earn money by providing embedded advertisement. These innovative business strategies may enhance the users' perception of usefulness. 
Table 2. Influence of BM Strategies on User Acceptance

\begin{tabular}{|l|l|l|l|}
\hline & HiPiHi & Uworld & Novoking \\
\hline $\begin{array}{l}\text { Business } \\
\text { Model (BM) }\end{array}$ & (PU-EFE)- & (PU-EFE)+ & (PU-EFE)+ \\
\hline
\end{tabular}

Note: “+” means positive; “-” means negative; “ ” means average impact.

Game Model: Like Second Life, HiPiHi emphasizes free creation. HiPiHi users may spend several hours to learn this complex creation system. However, this free creation model may support users' intrinsic motivations, such as enjoyment [28]. Novoking and Uworld have developed several models (e.g., models of cars), which can be used directly. Novoking also supports offline creation. People can design buildings by "3DMAX" and upload them to the Web 3.0 platform. These strategies can enhance the users' efficiency, but may reduce the users' enjoyment.

Table 3. Influence of GM Strategies on User Acceptance

\begin{tabular}{|l|l|l|l|}
\hline & HiPiHi & Uworld & Novoking \\
\hline \multirow{2}{*}{\begin{tabular}{l} 
Game \\
\multirow{2}{*}{ Model (GM) }
\end{tabular}} & $($ PEN $)+$ & $($ PEN $)-$ & $($ PEN $)-$ \\
& $($ PEOU-LEA)- & $($ PEOU-LEA $)+$ & $($ PEOU-LEA $)+$ \\
\cline { 2 - 4 } & (PU-EFI)- & $($ PU-EFI $)+$ & $($ PU-EFI $)+$ \\
\hline
\end{tabular}

Note: “+” means positive; “-” means negative; “ ” means average impact.

Web 3.0 platform Culture (VWC): Uworld has advantages on Web 3.0 platform culture strategies. First, Uworld has established virtual "Kala OK" room. Users' avatars can sing with other friends in virtual rooms. This strategy may enhance the social network of users. Second, it has established a team to manage the virtual society rules. The impolite posts, figures and clubs will be forbidden and deleted by managing teams. Furthermore, Uworld got the formal support from Chinese government in 2009. In China, government formal support can enhance the positive social norms on this Web 3.0 platform.

Table 4. Influence of VWC Strategies on User Acceptance

\begin{tabular}{|l|l|l|l|}
\hline & HiPiHi & Uworld & Novoking \\
\hline \multirow{2}{*}{$\begin{array}{l}\text { Web 3.0 platform } \\
\text { Culture(VWC) }\end{array}$} & (SN-INP)- & (SN-INP)+ & $($ SN-INP) \\
\cline { 2 - 4 } & (PU-EFI) & (PU-EFI)+ & (PU-EFI)- \\
\hline
\end{tabular}

Note: “+” means positive; “-” means negative; “ ” means average impact.

\section{DISCUSSION}

\subsection{Different Strategies of Three Platforms}

HiPiHi, Uworld, and Novoking have provided different strategies which may impact on user acceptance. We first compared the different strategies of the three companies for which the comparison results are illustrated in Table 5. 
Table 5. Different Strategies of Three Web 3.0 platforms

\begin{tabular}{|c|c|c|c|}
\hline & HiPiHi & Uworld & Novoking \\
\hline $\begin{array}{l}\text { Technology } \\
\text { Solution (TS) }\end{array}$ & $\begin{array}{l}\text { 1. Chinese Version } \\
\text { 2. Complex Functions } \\
\text { 3. High network speed } \\
\text { requirement } \\
\text { 4. High hardware } \\
\text { requirement }\end{array}$ & $\begin{array}{l}\text { 1. Chinese Version } \\
\text { 2. Simple Functions } \\
\text { 3. Average network } \\
\text { speed requirement } \\
\text { 4. Average hardware } \\
\text { requirement }\end{array}$ & $\begin{array}{l}\text { 1. Chinese Version } \\
\text { 2. Simple Functions } \\
\text { 3. Low network speed } \\
\text { requirement } \\
\text { 4. Low hardware } \\
\text { requirement }\end{array}$ \\
\hline $\begin{array}{l}\text { Business Model } \\
\text { (BM) }\end{array}$ & 1. Selling virtual land & $\begin{array}{l}\text { 1. Flexible business } \\
\text { strategy }\end{array}$ & $\begin{array}{l}\text { 1. Flexible business } \\
\text { strategy }\end{array}$ \\
\hline $\begin{array}{l}\text { Game Model } \\
\text { (GM) }\end{array}$ & $\begin{array}{l}\text { 1. Centralizing inhabits } \\
\text { 2. Complex creation } \\
\text { system } \\
\text { 3. Rare tasks }\end{array}$ & $\begin{array}{l}\text { 1. Centralizing inhabits } \\
\text { 2. Simple creation system } \\
\text { 3. Providing tasks to new } \\
\text { users }\end{array}$ & $\begin{array}{l}\text { 1. Pre-existing cities } \\
\text { 2. Simple creation system } \\
\text { 3. Providing tasks to new } \\
\text { users }\end{array}$ \\
\hline $\begin{array}{l}\text { Web 3.0 } \\
\text { platform } \\
\text { Culture (VWC) }\end{array}$ & $\begin{array}{l}\text { 1. High freedom in society } \\
\text { rules } \\
\text { 2. Average social network } \\
\text { support }\end{array}$ & $\begin{array}{l}\text { 1. Low freedom } \\
\text { 2. High social network } \\
\text { support (virtual Kala } \\
\text { OK room) }\end{array}$ & $\begin{array}{l}\text { 1. Low freedom in } \\
\text { society rules } \\
\text { 2. Low social network } \\
\text { support }\end{array}$ \\
\hline
\end{tabular}

\subsection{Different Orientations of Three Web 3.0 Platforms}

Based on the above analysis, we can summarize the different orientations of three Web 3.0 platforms, for which the results are illustrated in Table 6. We found that HiPiHi is an "entertainment-oriented" Web 3.0 platform, as its strategies have strong influence on perceived enjoyment. Uworld is a "social-oriented" Web 3.0 platform, as its strategies have strong influence on subject norms. Novoking is an "utilitarian-oriented" Web 3.0 platform, as its strategies have strong influence on perceived ease of use, and perceived usefulness. However, the relationship between orientations of Web 3.0 platforms and their performance in the Chinese market is still ambiguous. As Chinese Web 3.D market is emerging, we can not compare the current performance of these Web 3.0 platforms. As the development of Web 3.0 platforms in China continues, empirical studies should be applied to compare the performance of Web 3.0 platforms in the long-run.

Table 6. Different Orientations of Three Platforms

\begin{tabular}{|c|c|c|c|c|c|}
\hline & $\begin{array}{c}\text { Perceived } \\
\text { Enjoyment }\end{array}$ & $\begin{array}{c}\text { Subject } \\
\text { Norm }\end{array}$ & $\begin{array}{c}\text { Perceived } \\
\text { Ease of Use }\end{array}$ & $\begin{array}{c}\text { Perceived } \\
\text { Usefulness }\end{array}$ & Orientation \\
\hline HiPiHi & Strong & Average & Weak & Weak & Entertainment \\
\hline Uworld & Average & Strong & Average & Average & Social \\
\hline Novoking & Weak & Weak & Strong & Strong & Utilitarian \\
\hline
\end{tabular}




\subsection{Limitations and Future Study}

Despite some significant findings from observation, the limitation of this study is that is lacks empirical evidence, because these Web 3.0 platforms have conducted business in China for only a short time. For example, Uworld started from 2005, while HipiHi and Novoking started from 2006. It is different to conduct a statistical model to explain the long-term effects of different strategies.

As the development of Web 3.0 platforms in China continues, some empirical studies should be applied to investigate the relationship between Web 3.0 platform orientations and their performance, such as survey, experiment, and long-term statistical analysis. And some more rigorous models of user acceptance of Web 3.0 in China should be integrated.

\section{CONCLUSION}

In this research, we compared different strategies of HiPiHi, Uworld, and Novoking to investigate how four strategies of Web 3.0 platforms (i.e., technology solutions, business model, game model, and Web 3.0 platform culture) potentially impact on three dimensions of user acceptance behavior; we have also sought to find out which strategies would better suit the Chinese environment. Based on comparison, we found that three Web 3.0 platforms have three different orientations: 1) HiPiHi is entertainment-oriented; 2) Uworld is social-oriented; and 3) Novoking is utilitarian-oriented. The strategies of these three Web 3.0 platforms have different influences on Chinese user acceptance behavior. Currently, it is hard to draw conclusion of which Chinese Web 3.0 platform will succeed in this emerging market. Future studies should investigate the relationship between Web 3.0 platform orientations and their performance in the Chinese market.

\section{ACKNOWLEDGMENT}

The work described in this paper was supported by the Project Funds for Youth, Institute of Policy and Management, Chinese Academy of Sciences (No: O900971J01). 
International Journal of Computer Science \& Information Technology (IJCSIT), Vol 3, No 3, June 2011

APPENDix 1. CODING SCHEME

\begin{tabular}{|l|l|l|l|}
\hline \multicolumn{1}{|c|}{ Construct } & \multicolumn{1}{|c|}{ Code } & \multicolumn{1}{|c|}{ Measure } & \multicolumn{1}{|c|}{} \\
\hline 1. Perceived Ease of Use & PEOU & Skillfulness & PEOU-SKI-XX \\
\hline & & Quickness & PEOU-QUI-XX \\
\hline 2. Perceived Usefulness & PU & Learning & PEOU-LEA-XX \\
\hline & & Efficiency & PU-EFE-XX \\
\hline 3. Perceived Enjoyment & PEN & Enjoyable & PU-EFI-XX \\
\hline & & Pleasant & PEN-ENJ-XX \\
\hline & & Fun & PEN-PLE-XX \\
\hline 4. Subject Norms & & Influencing People & SN-INP-XX \\
\hline & & Important People & SN-IMP-XX \\
\hline
\end{tabular}

Note: XX=Related Strategies (Technology Solution, Business Model, Game Model and Web 3.0 platform Culture)

\section{REFERENCES}

[1] M. Fetscherin and C. Lattemann, "User Acceptance of Web 3.0 platforms: An Explorative Study about Second Life," Second Life Research Team 2007.

[2] S. Baker, "Web 3.0," BusinessWeek, vol. October 24, 2007.

[3] D. Terdiman, "A Brief History of the Web 3.0 platform," CNET News.com, vol. November 9, 2006.

[4] M. W. Peng, "Towards an Institutional-Based View of Business Strategy," Asia Pacific Journal of Management, vol. 19, pp. 251-267, 2002.

[5] C. Oliver, "Sustainable Competitive Advantage: Combing Institutional and Resource-Based Views," Strategic Management Journal, vol. 18, pp. 679-713, 1997.

[6] W. R. Scott, Institutions and Organizations. Thousan Oaks,CA: Sage, 1995.

[7] G. Redding, "The thick description and comparison of societal systems of capitalism," Journal of International Business Studies, vol. 36, pp. 123-155, 2005.

[8] E. Sathiyamoorthy, N. C. S. N. Iyenger, and V. Ramachandran, "Agent Based Trust Management Framework in Distributed E-Business Environment," International Journal of Computer Sciences \& Information Technology, vol. 2, pp. 14-28, 2010. 
International Journal of Computer Science \& Information Technology (IJCSIT), Vol 3, No 3, June 2011

[9] W. Reinartz, M. Krafft, and W. D. Hoyer, "The Customer Relationship Management Process: Its Measurement and Impact on Performance," Journal of Marketing Research, vol. 41, pp. 293$305,2004$.

[10] A. Payne and P. Frow, "A Strategic Framework for Customer Relationship Management," Journal of Marketing, vol. 69, pp. 167-176, 2005.

[11] F. D. Davis, "Perceived Usefulness, Perceived Ease of Use, and User Acceptance of Information Technology," MIS Quarterly, vol. 13, pp. 319-340, 1989.

[12] H. Lou, W. Luo, and D. Strong, "Perceived Critical Mass Effect on Groupware Acceptance," European Journal of Information Systems, vol. 9, pp. 91-103, 2000.

[13] C. L. Hsu and H. P. Lu, "Why DO People Play On-line Games? An Extended TAM with Social Influences and Flow Experience," Informaton \& Management, vol. 41, pp. 853-868, 2004.

[14] Y. Hwang, "Investigating Enterprise Systems Adoption: Uncertainty Avoidance, Intrinsic Motivation, and the Technology Acceptance Model," European Journal of Information Systems, vol. 14, pp. 150-161, 2005.

[15] I. Ha, Y. Yoon, and M. Choi, "Determinants of Adoption of Mobile Games Under Mobile Broadband Wirelesss Access Environment," Information \& Management, vol. 44, pp. 276-286, 2007.

[16] A. K. Hamada, M. Z. Rashad, and M. G. Darwesh, "Behavior Analysis in a Learning Environment to Identify the Suitable Learning Style," International Journal of Computer Sciences \& Information Technology, vol. 3, pp. 48-59, 2011.

[17] V. S. Moertini, A. A. Athuri, H. M. Kemit, and N. Saputro, "The Development on Electronic Payment System for Universities in Indonesia: On Resolving Key Success Factors," International Journal of Computer Sciences \& Information Technology, vol. 3, pp. 16-33, 2011.

[18] M. Kayri and O. Cakir, "An Applied Study on Educational Use of Facebook as a Web 2.0 Tool: The Sample Lesson of Computer Networks and Communication," International Journal of Computer Sciences \& Information Technology, vol. 2, pp. 48-58, 2010.

[19] P. Legris, J. Ingham, and P. Collerette, "Why do People Use Information Technology? A Critical Review of the Technology Acceptance Model," Information \& Management, vol. 40, pp. 191-204, 2003.

[20] B. Szajna, "Empirical Evaluation of the Revised Technology Acceptance Model," Management Science, vol. 42, pp. 85-92, 1996.

[21] V. Venkatesh and M. Morris, "Why Don't Men Ever Stop to Ask for Directions? Gender, Social Influence, and Their Role in Technology Acceptance and User Behavior," MIS Quarterly, vol. 24, pp. 115-139, 2000.

[22] A. M. Rubin, "Media Uses and Effects: A Uses-and-Gratifications Perspective," in Media Effects: Advances in Theory and Research, J. Bryant and D. Zillmann, Eds. Hillsdale, NJ: Lawrence Erlbaum Associates, 1994.

[23] C. W. Holsapple and J. Wu, "User acceptance of Web 3.0 platforms: the Hedonic framework," The DATA BASE of Advances in Information Systems, vol. 38, pp. 86-89, 2007.

[24] H. Van der Heijden, "User acceptance of hedonic information systems," MIS Quarterly, vol. 28, pp. 695-704, 2004.

[25] V. Venkatesh, M. G. Morris, G. B. Davis, and F. D. Davis, "User Acceptance of Informaiton Technology: Toward a Unified View," MIS Quarterly, vol. 27, pp. 425-478, 2003.

[26] M. Koufaris, "Applying the Technology Acceptance Model and Flow Theory to Online Consumer Behavior," Information Systems Research, vol. 13, pp. 205-223, 2002. 
International Journal of Computer Science \& Information Technology (IJCSIT), Vol 3, No 3, June 2011

[27] R. Tesch, Qualitative Research: Analysis Types and Software Tools. New York: Falmer, 1990.

[28] R. Shroff, D. Vogel, J. Coombes, and F. Lee, "Student e-Learning Intrinsic Motivation: a Qualitative Analysis," Communications of the AIS, vol. 19, pp. 241-260, 2007.

\section{Authors}

$\mathrm{Xi}$ Zhang is an Assistant Professor in the Institute of Policy and Management, Chinese Academy of Sciences. He got PhD degree major in MIS from Department of Information Systems, City University of Hong Kong, and $\mathrm{PhD}$ degree major in Management Science from University of Science and Technology of China (USTC). His research focuses on social Web 3.0 platform, distributed work, knowledge management, and innovation management in Chinese enterprises, with more than 30 publications in top international journals and conferences, such as Journal of Management Information Systems, IEEE Transactions on Engineering Management, Journal of Social Psychology, Journal of Applied Social Psychology, HICSS, ECIS, PACIS, etc.

Doug Vogel is Professor (Chair) of Information Systems and an AIS Fellow. He received his M.S. in Computer Science from U.C.L.A. in 1972 and his Ph.D. in Information Systems from the University of Minnesota in 1986. He started his professional career as a software engineer in the aerospace industry and has also been a company General Manager and Board of Director member in addition to establishing a career as an academic. Professor Vogel has published widely and directed extensive research on group support systems, knowledge management and technology support for education. His research interests bridge the business and academic communities in addressing questions of the impact of information systems on aspects of interpersonal communication, group problem solving, cooperative learning, and multi-cultural team productivity and knowledge sharing. Prof. Vogel is a member of the IEEE and President of the Hong Kong Chapter of the AIS. 